Clinical Medicine

Poster

Abstract ID: 12

\title{
Survival analysis of surgically treated laryngeal cancer in Hospital Tengku Ampuan Afzan, Kuantan, Pahang from January 2002 to June 2013
}

\author{
Kahairi Abdullah ${ }^{\mathrm{a}}$ | Raja Ahmad ${ }^{\mathrm{a}}$ | Jamalludin Abdul Rahman ${ }^{\mathrm{b}}$ | Zamzil Amin Asha'ari ${ }^{\mathrm{a}}$ | Mohd Sayuti \\ Razali $^{\mathrm{a}}$ | Wan Ishlah Wan Leman ${ }^{\mathrm{a}}$ \\ ${ }^{a}$ Department of Otolaryngology-Head \& Neck Surgery, Kulliyyah of Medicine, International Islamic \\ University Malaysia \\ ${ }^{b}$ Department of Community Medicine, Kulliyyah of Medicine, International Islamic University \\ Malaysia
}

Introduction: Laryngeal cancers are one of the most prevalent head and neck cancer in Malaysia. However, little information is available on survival rate for larynx cancer in Malaysia has been reported. The purpose of the present study was to evaluate the survival and the prognostic factors in surgically treated patient with laryngeal cancer in Hospital Tengku Ampuan Afzan, Kuantan, Pahang. Methods: Retrospective analysis of surgically treated patient of laryngeal cancer treated in Hospital Tengku Ampuan Afzan during January 2002 to June 2013 was analyzed. The overall survival rate was measured using the Kaplan Meier method. Prognostic factor was identified by log rank test taking $p$ value $<0.05$ as statistical significance. Results: A total 36 cases were analyzed. Two-thirds $(86.1 \%)$ of the cases were at an advanced stage (stage III \& IV) at presentation. The 2, 5 and 10 year overall survivals for the laryngeal cancer were $62 \%, 34 \%$ and $22 \%$ respectively. The histopathological examination result was the strongest prognostic factors in laryngeal cancer. Conclusions: The results revealed remarkably poor outcomes of the patients in the series, indicating a strong need to increase the proportion of early stage presentations and maximize the treatment efficacy to improving outcomes.

KEYWORDS: Head and neck, laryngeal cancer, survival, prognosis 